\title{
Evaluation of Artistic Lighting Combining LED Light and Glass Art by Psychological Experiment
}

\author{
Ryohei Nakatsu $^{1 *}$, Naoko Tosa ${ }^{1}$, Takashi Kusumi ${ }^{1}$, Satoru Okagaki ${ }^{2}$, Haruna Yamazaki ${ }^{2}$, \\ Muneharu Kuwata ${ }^{2}$, Takashi Hirai ${ }^{3}$ \\ ${ }^{1}$ Kyoto University, Yoshidahonmachi, Sakyo, Kyoto, Japan \\ ${ }^{2}$ Advanced Technology R\&D Center, Mitsubishi Electric \\ ${ }^{3}$ Kyoto University, Kyoto Daigaku-Katsura, Nishikyo-ku, Kyoto, Japan
}

*Corresponding Author: Ryohei Nakatsu, Kyoto University, Yoshidahonmachi, Sakyo, Kyoto, Japan

\begin{abstract}
We have been working on the creation of glass art and also art lighting by combining glass art with an LED light source. To investigate how people feel and evaluate such art lighting in a working environment and relaxing environment, we have carried out a psychological experiment comparing two types of art lighting we have created and ordinary LED light. Twenty-four subjects were asked to fill in questionnaires to evaluate each lighting and the result was analyzed by comparing the mean value of the evaluation scores and also the results of the t-test. It was revealed that art lighting is very effective in various relaxing environments. At the same time, it was found that art lighting has the capability of making people creative in working environments.
\end{abstract}

\section{INTRODUCTION}

Lighting has played a major role in our lives by relaxing people at home, making work efficient in the office, and softening communication among people. What kind of lighting is to be used in various situations, such as at homes, offices, and hotels, is an important theme, and many studies have been conducted. Especially in recent years, LED lighting is replacing conventional lighting in many places due to its characteristics such as durability and low power consumption. Also, Because LEDs can be downsized and various colors can be produced using a huge number of LED chips consisting of the three primary colors, a large LED screen could be realized. Combining many LED chips of multiple colors can beautifully illuminate areas such as shopping centers where people gather. The idea of using LED lighting to create a space that is rich in design and art is considered to be the basis of such usage of LED lighting. As an extension of these current lighting methods, it would be possible to create a new type of lighting that combines LED lighting and art. That is the reason for starting this research.

Glass has a good affinity with lighting because of its transparency, the ability to create various shapes, and the ability to add various colors, and many design products and artworks using glass have been created in the past. In that sense, it is expected that the combination of LED lighting and glass art would create new lighting and would have the effect of calming and relaxing people and even improving work efficiency.

This paper has the following structure. First, Section 2 describes related research and activities such as lighting evaluation research and the current state of glass art. Section 3 describesthe fluid art that Naoko Tosa, one of the authors, has been creating, and also as its extension describes the glass art and the lighting using the glass art. Section 4 describes the content of a psychological experiment comparing several lightings using glass art and ordinary LED lighting. Section 5describes the analysis results of the data obtained as a result of the experiment and the consideration of it. Finally, Section 6 concludes the paper.

\section{RELATED RESEARCH AND ACTIVITIES}

As related research and activities, this section describes the psychological evaluation research on how people feel lighting and the history and current status of glass art. 


\subsection{Research on the Effects of Lighting on People}

In living spaces and office spaces, lighting has a great influence on people who live there and/or work there, such as relaxing people, reducing stress, and improving work efficiency. Therefore, psychological experiments have been conducted using many subjects to see how people feel by changing lighting conditions in various situations [1][2][3][4]. In these experiments, the subjectswere asked tofill in questionnaires comparing various variations of ordinary lighting, and the results were statistically analyzed to evaluate how the average person feels.

On the other hand. there are several evaluations of artworks through psychological experiments [5][6]. But there seems to be no example of trying to evaluate artistic lighting. Our research is considered to have great significance in that sense.

\subsection{History and Current Status of Glass Art}

Glass has been used in the form of crafts and art for a long time because it is possible to realize various colors by adding pigments in addition to its capability of transparency and process ability. Its origin dates far back to the Syrian-Mesopotamia era around $2250 \mathrm{BC}$ [7].

Glasswork creation methods are divided into hot work performed by melting or softening glass and cold work performed at room temperature. Hot work consists of a hot cast and a blown glass. In the hot cast, a prototype made of clay or wax is cast with fire-resistant gypsum, and molten glass is poured into it for casting. For the blown glass a person blows breath into the glass seed wound on a blowing rod to inflate it. There are other methods such as burner work that uses a burner, and kiln work that causes thermal deformation in a gas furnace or electric furnace. On the other hand, as for cold work, various methods such as cut glass, sandblast, and glass etching is known by subjecting glass at room temperature to various processes. For example, the method of making stained glass belongs to cold work.

Until now, the above-mentioned methods have been the mainstream of creating glassworks. But recently, many glass art productions have been carried out aiming to make a pure artwork. Dale Chihuly is known as a representative artist of such glass art production [8]. He became world-famous for producing large-scale glass art while making full use of hot work techniques. Figure 1 shows an example of Chihuly's glass artworks.

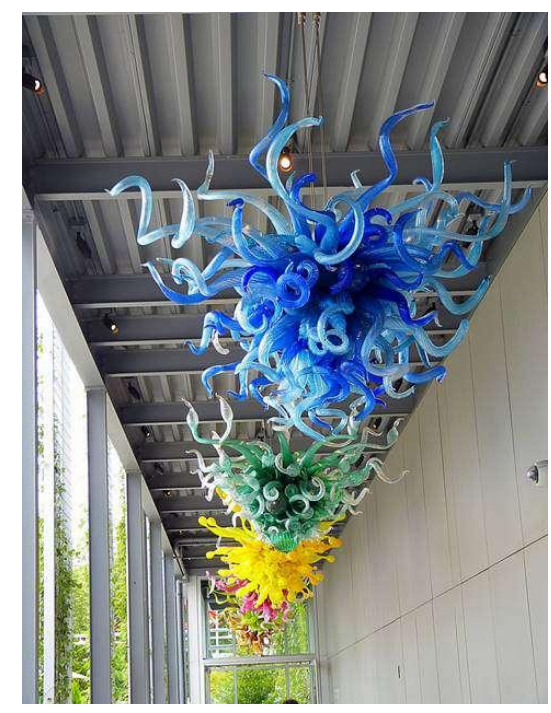

Fig1. Example of Chihuly's glass art.

\section{Fluid ART AND Glass ART AS ITS EXTENSION}

In this section, the fluid art, for which one of the authors, Naoko Tosa, has been working, and her representative fluid art, the video art called "Sound of Ikebana," is described. Also, the glass art she has been creating as a materialization of the Sound of Ikebanais described.

\subsection{Fluid Art}

How fluids behave is an important subject of physics research and has been called "fluid dynamics [9]." It is well known that fluids produce extremely beautiful shapes under various conditions. Beauty 
is a basic element of art. Therefore, it is natural to consider using fluid dynamics as a basic methodology for art generation. The authors call the art created by shooting various behaviors of fluid with a high-speed camera as "fluid art," and have been making various fluid artworks.

The idea of creating fluid art was inspired by the "milk crown." It is well known that when a milk grain is dropped on milk and the phenomenon is shot with a high-speed camera, a beautiful shape like a crown called a "milk crown" is created (Fig. 2). Section 3.2 describes an example of art production called "Sound of Ikebana" [10][11] inspired by this physical phenomenon.

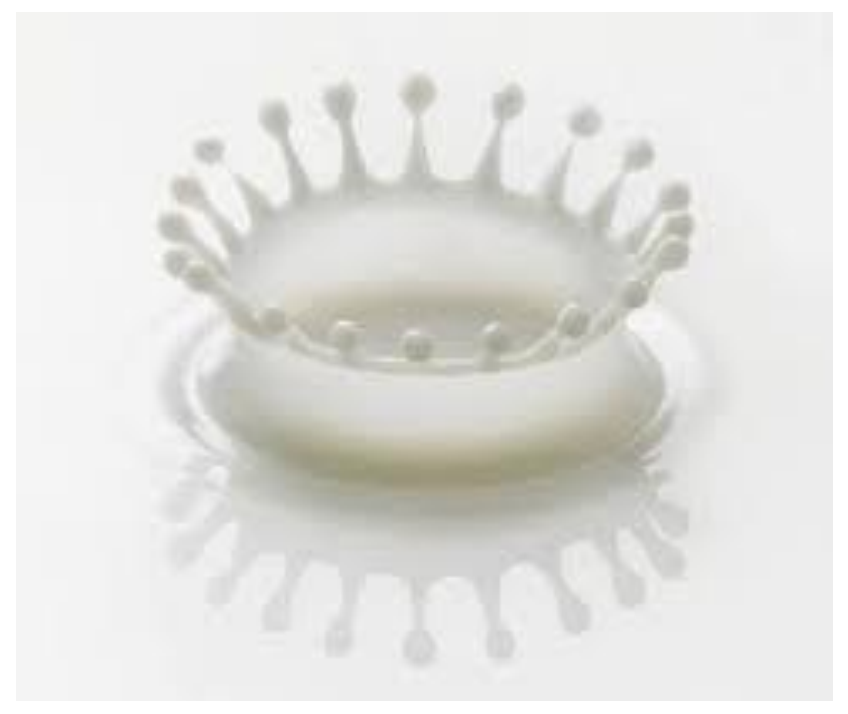

Fig2. Milk crown.

\subsection{Fluid Art "Sound of Ikebana"}

Naoko Tosa has found that a fluid such as paint can create an Ikebana-like shape by being vibrated by sound and being shot with a high-speed camera. First, a speaker is set in a face-up way, a thin rubber film is put on top, fluid such as paint is put on it, and the speaker is vibrated with sound (Fig. 3).Then the paint jumps up and various shapes are created.

black background

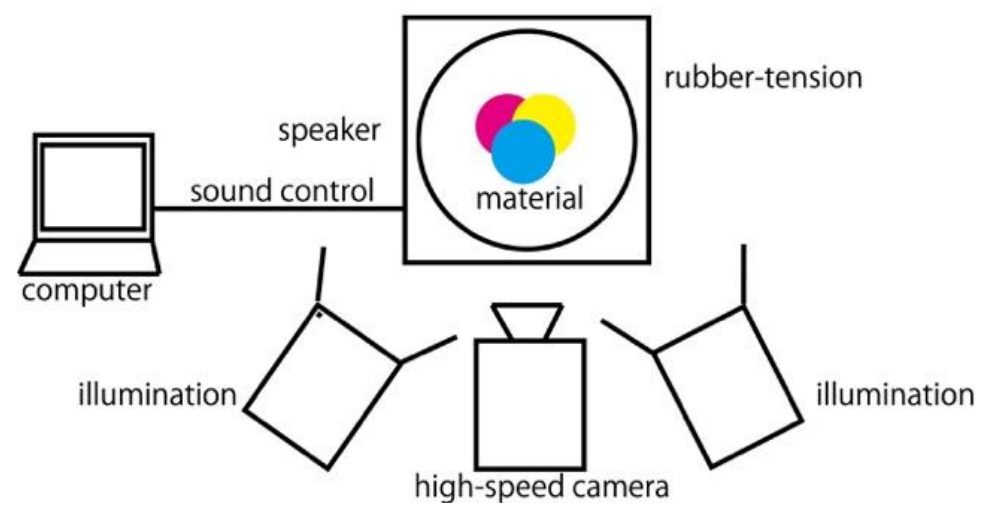

Fig3. Top-down view of the Sound of Ikebana creation system.

She confirmed that various fluid shapes can be generated by changing the sound shape, sound frequency, fluid type, fluid viscosity, etc. using this environment. The video obtained in this way was edited to match the colors of the Japanese season, and a video artwork called "Sound of Ikebana" was created [10][11]. Figure 4 is one scene from the artwork. Also, in April 2017, she exhibited it using more than 60 digital billboards at Times Square in New York as part of her mission as Japan Cultural Envoy named by the Agency for Cultural Affairs, the Japanese government. This is an event called Times Square Midnight Moment, where one artist's video art is shown every night for one month. The event is shown in Fig. 5. 


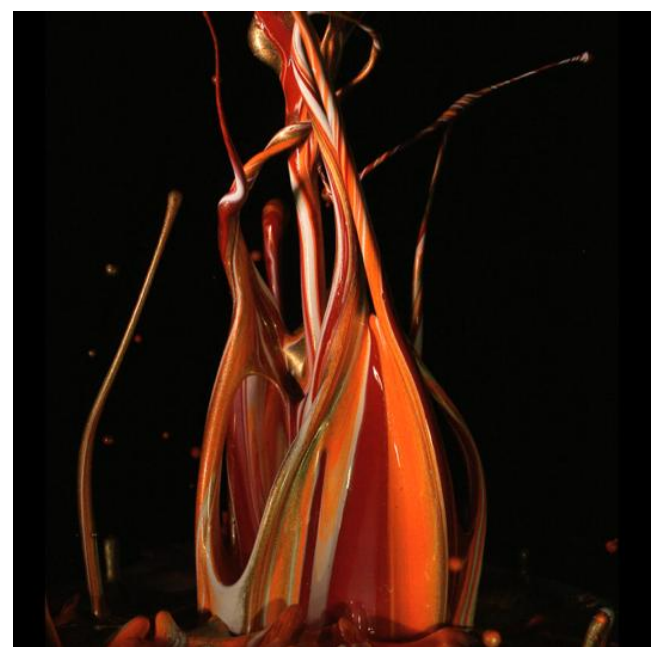

Fig4. Scene of "Sound of Ikebana."

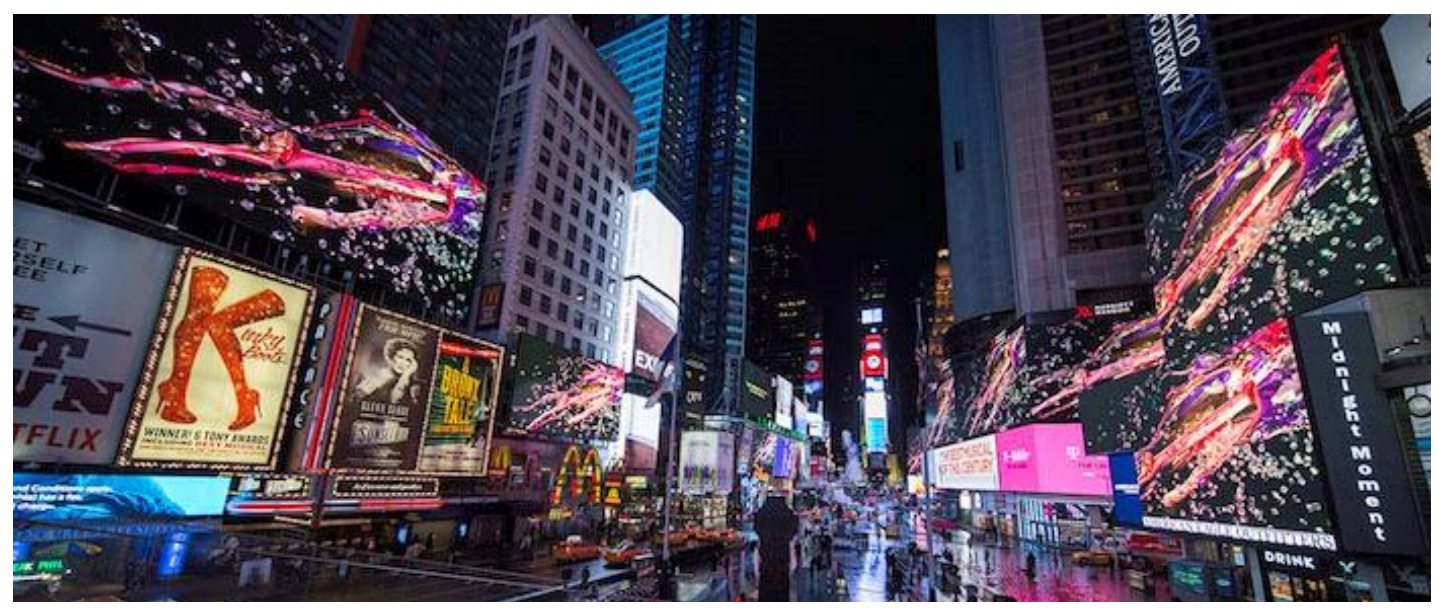

Fig5. Showing of "Sound of Ikebana" at Times Square, New York.

What was interesting to the authors was that the above video art raised questions of what beauty is and especially what Japanese beauty is. When Tosa exhibited the media art in various cities of the world, many overseas art-related people said, "Tosa's media art is an abstract representation of beauty hidden in physical phenomena. It expresses a beauty that Westerners have not noticed so far, and that is the expression of Japanese consciousness and sensitivity." After returning to Japan, by discussing with many Japanese art critics, curators, researchers, etc., many people agreed with this idea. The authors think this is an important opinion closely related to the substantial questions such as what art is and what beauty is, and the authors are trying to approach such a problem while using AI [12].

\subsection{Sound of Ikebana as Glass Art}

Many people feel the Japanese beauty in the Sound of Ikebana, and many of them have the opinion that it is interesting if the Sound of Ikebana can be realized as a three-dimensional object rather than just an image. The following can be considered as methods to realize this.

(1) 3D reconstruction using images from multiple cameras

This is a method of creating a three-dimensional model of a phenomenon by preparing multiple cameras around the object and finding corresponding points on multiple images obtained from them. This method is possible to generate a three-dimensional model with considerable accuracy for a stationary object or a slow-moving object. However, in the case of a phenomenon such as the Sound of Ikebana that occurs at high speed and cannot be captured without using a high-speed camera, precise three-dimensional reconstruction is difficult. The authors are currently attempting to construct a three-dimensional model by installing multiple high-speed cameras in the environment that produces the Sound of Ikebana and shooting them in synchronized high-speed cameras [13].

(3) Generation of the Sound of Ikebana by glass

In parallel with the above-mentioned attempts, we have been attempting to create shapes similar to the 
Sound of Ikebana with glass. We have been trying two methods.

In one method we think that the actual flower arrangement combines multiple types of flowers and plants to make one work. So, we think that the glass version of the Sound of Ikebana is also composed of multiple parts, make each part with glass, and combine them. By doing so, we try to create a threedimensional object similar to the Sound of Ikebana.

We use hot work to create the organic shape of the Sound of Ikebana. Similar to the blown glass production method, the glass seeds heated in the melting furnace are wound on a blowing rod, but instead of blowing a breath like a blown glass to create a hollow shape, various processes can be carried out by twisting or hanging a soft glass. We also tried coloring the glass art created by adding various pigments in the process. Figure 6 shows several examples of the created glass art; glass artwork type 1.
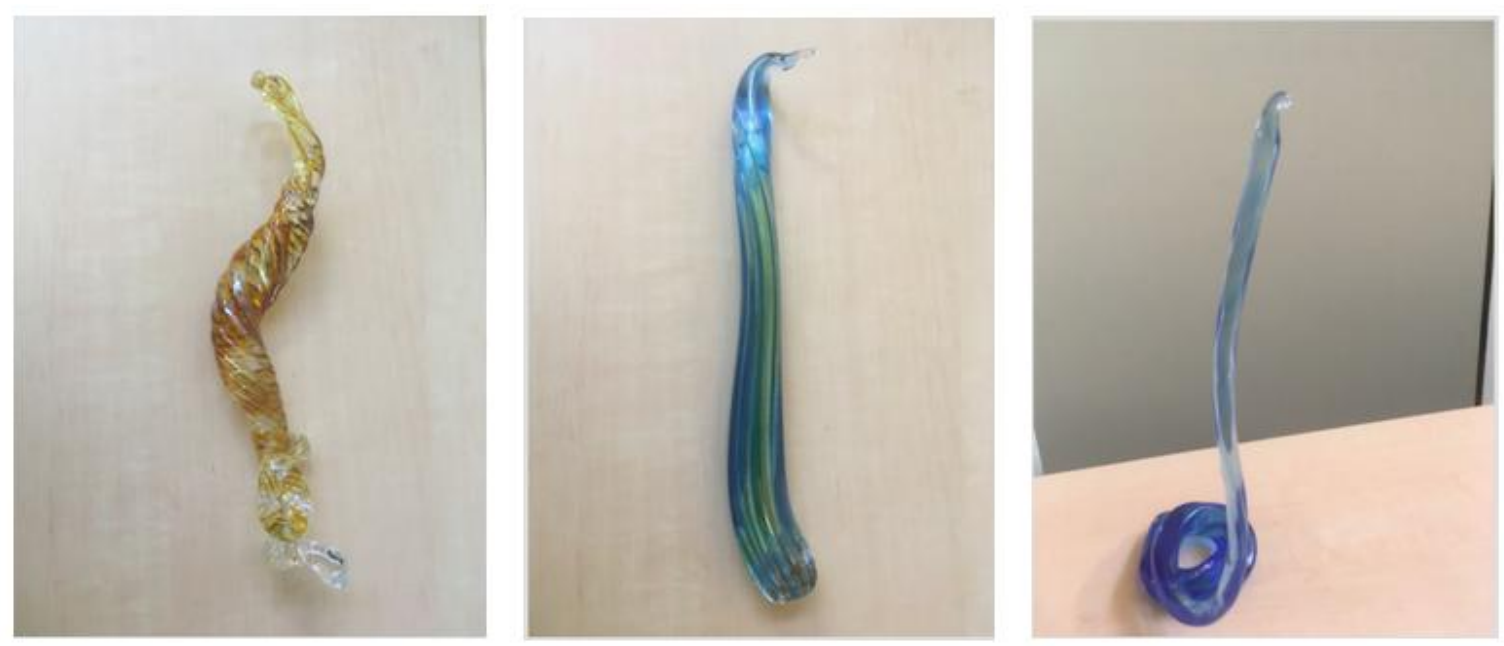

Fig6. Examples of produced glass artwork type 1.

In another method, we were interested in the phenomenon of melting glass sagging down due to gravity. We thought that there is a similarity between the jumping up of paints against the gravity and the sagging down of melted glass due to the gravity. We put warmed and softened glass on a mesh then the softened glass sagged down. Figure 7 shows an example of this phenomenon and Fig. 8 shows several examples of created glass art; glass artwork type 2 .

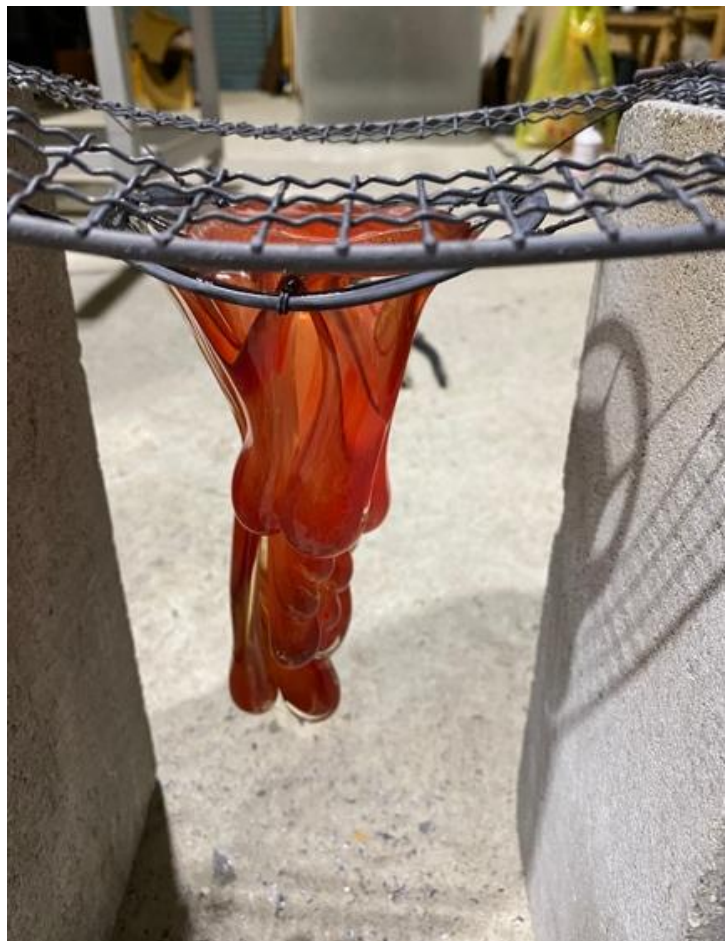

Fig7. An example of melted glass sagging down from a mesh. 

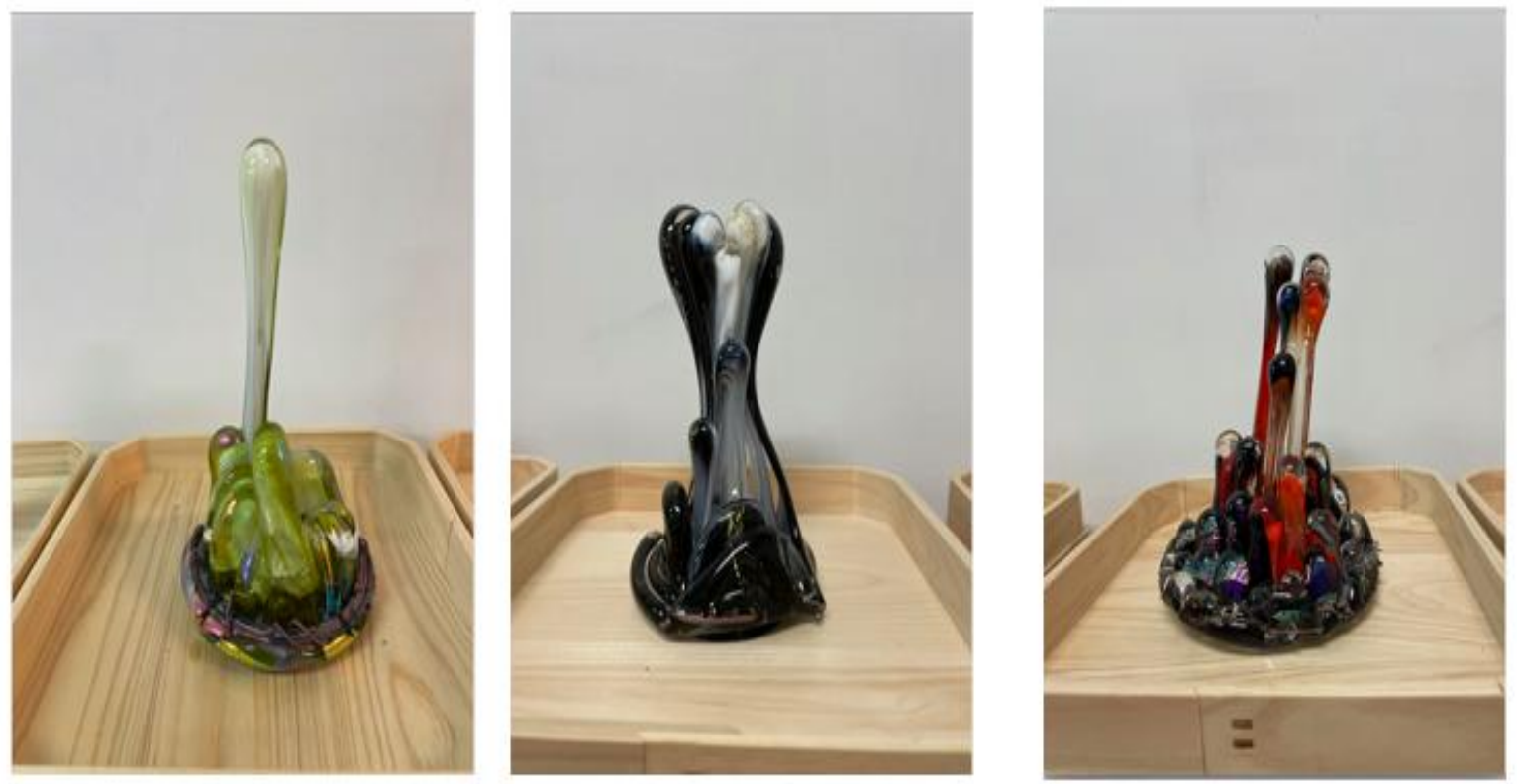

Fig8. Examples of produced glass artwork type 2.

Interestingly, we found a similar relationship in Antoni Gaudi's work. In the designing process of the famous Sagrada Familia, Gaudi hung strings from the ceiling, tied small sandbags to them, and tied the strings to each other letting gravity make the arch shapes, which were later used for the form of the spires of Sagrada Familia (Fig. 9).
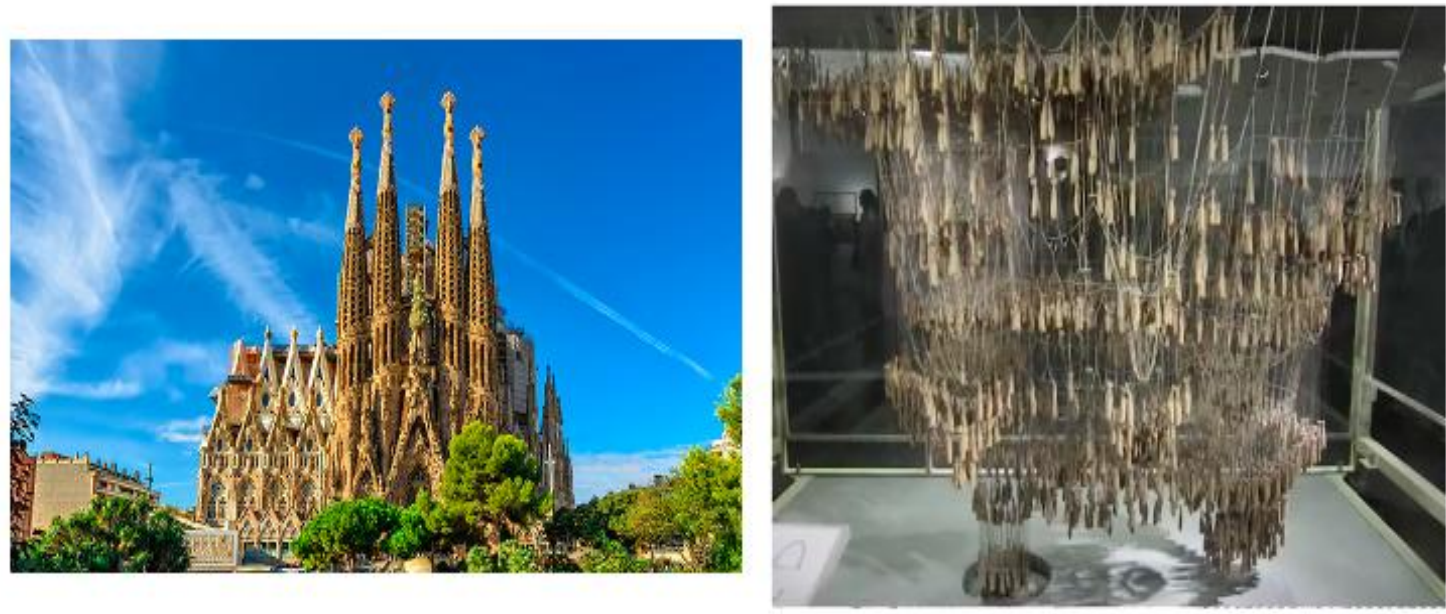

Fig9. Sagrada Familia(left) and Gaudi's designing experiment using strings and sandbags (right). (in public domain)

In the next section, we describe our psychological experiment to evaluate art lighting made from these glass artworks.

\section{PSYChOlOGiCAl EXPERIMENT}

\subsection{Experimental Environment}

As an environment for conducting psychological experiments using art lighting, assuming a work environment (office, etc.) and a relaxing environment (living room, hotel lobby, etc.), we constructed two environments simulating them.

(1) Work environment

A desk and a chair were installed in our laboratory to simulate an office environment. A simple LED lighting was used (Fig. 10). Its brightness was 1000 lumens and the illuminance on the desk was about 900 lux, which was sufficient for office work. The subjects were asked to spend a few minutes in this environment while imagining doing office work such as checking e-mails, preparing documents, etc., and were asked to answer the questionnaire about their feelings. 


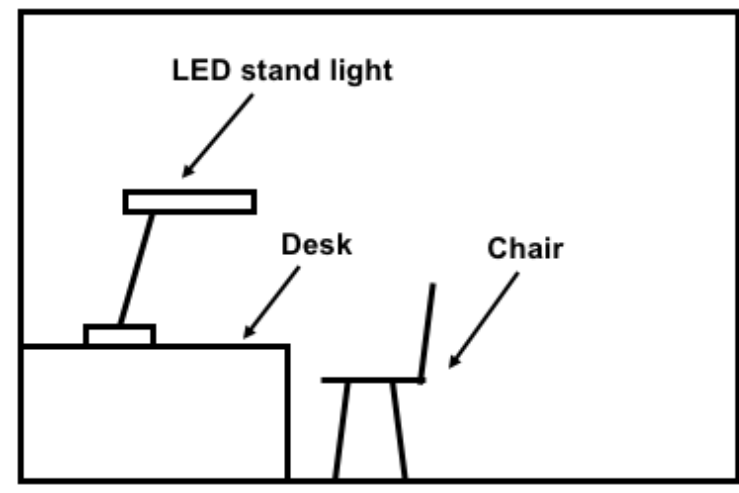

Fig10. Work environment.

(2) Relaxing environment

For a relaxing environment, a desk and a chair were set up in our laboratory and art lighting was used (Fig. 11). The subjects were instructed to watch the art lighting, and after sitting down at the desk for a few minutes, they were asked to respond to a questionnaire about their feelings. The illuminance at the subject's position was about 500 lux, which was a little dark environment for office work.

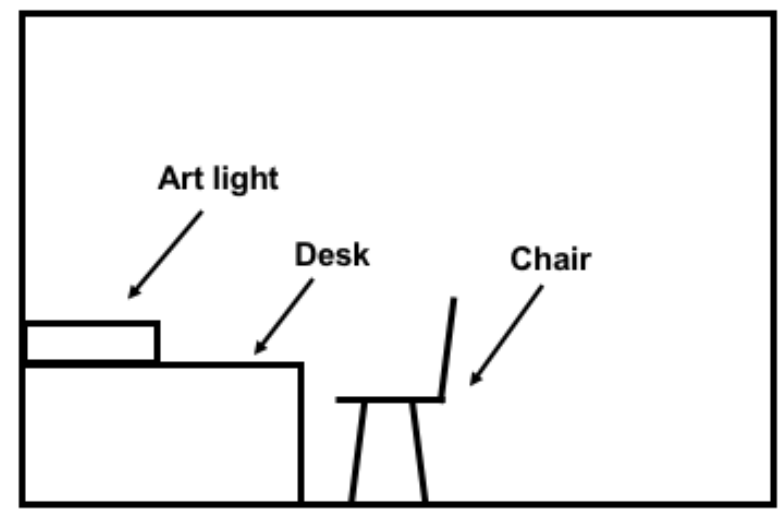

Fig11. Relaxing environment

The two types of art lightings that were used in the comparative experiment are shown in Figures 12 and 13. Art lighting 1 is a three-dimensional arrangement of the glass arts consisting of glass artwork type 1 and glass artwork type 2 described in Chapter 3 imitating Ikebana. The art lighting 1 was illuminated with LED lighting from below, and people can enjoy the effect of the light reflected from the glass art and the light transmitted through it. On the other hand, art lighting 2 is developed by arranging individual glass artworks in a circular board and it is illuminated from the rear with a horizontally long LED light. And by slowly rotating the circular board, we aimed to create a dynamic effect.

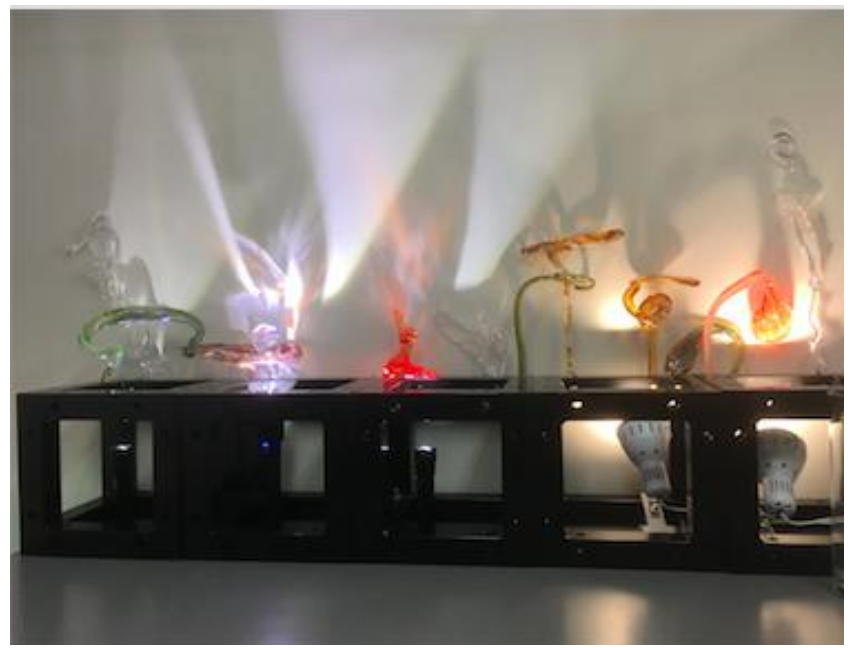

Fig12. Art lighting 1 


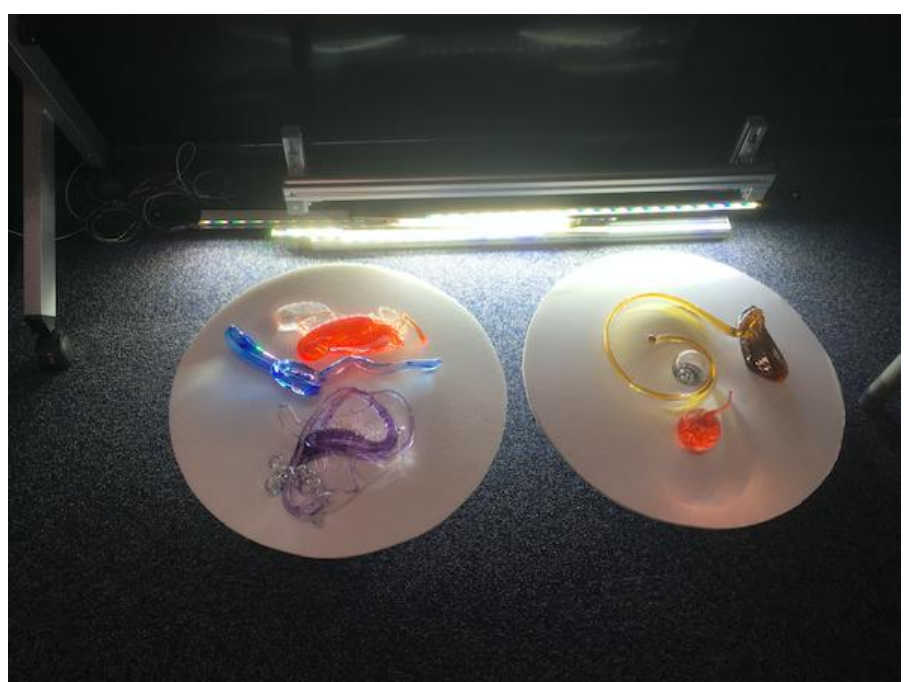

Fig13. Art lighting 2

\subsection{Subject}

19 students from Kyoto University (11 males, 8 females, age 20's) and 5 staff from Kyoto University ( 2 males, 3 females, age 20's -40 's), resulting in 24 people (13 males, 11 females) were used as subjects.

\subsection{Psychological Experiment Procedure}

The psychological experiment was conducted in the following procedure.

(1) Each subject was asked to spend 5 minutes in the work environment and answer the feelings felt at that time in a questionnaire.

(2) Each subject was asked to spend 5 minutes in the environment with art lighting 1 and to answer the feelings felt at that time in a questionnaire.

(3) Then each subject was asked to spend 5 minutes in the environment with art lighting 2 and to answer the feelings felt at that time in the questionnaire.

The order of each environment for each subject was fixed as the above rather than being set randomly. However, we tried to avoid the influence of the order effect by asking each subject to revise the questionnaire, if necessary, after the experiment. However, most subjects did not feel the need for modification.

\subsection{Questionnaire}

A questionnaire was used to evaluate the psychological effect of these environments, and the subjects were asked to fill the questionnaire on a 7-point scale. Regarding the question, we prepared three types of questions; "How did you feel about the lighting?" "What kind of effect does the lighting have?" "What kind of scene is the lighting suitable for?" The specific contents of the questions as shown in Table 1 were decided by referring to the other similar studies [1][2][4].

Table1. Contents of the questionnaire

\begin{tabular}{|c|c|}
\hline $\begin{array}{l}\text { 1. How did you feel about the lighting? } \\
\text { Comfortable - Uncomfortable } \\
\text { Friendly - Unfriendly } \\
\text { Beautiful - Not beautiful } \\
\text { Calm - Restless } \\
\text { Interesting - Boring } \\
\text { Warm - Cold } \\
\text { Changeable - Not changeable } \\
\text { Luxury - Sober } \\
\text { Unique - Mediocre }\end{array}$ & $\begin{array}{l}\text { W. What kind of effect does the lighting have? } \\
\text { I can relax - I can't relax } \\
\text { Ican be creative - Ican't be creative. } \\
\text { I feel energetic - I don't feel energetic } \\
\text { I can face difficulty - I can't face difficulty } \\
\text { I feel refreshed - I don't feel refreshed } \\
\text { 3. What kind of scene is the lighting suitable for? } \\
\text { Appropriate for sleeping - Inappropriate for sleeping } \\
\text { Appropriate for eating - Inappropriate for eating } \\
\text { Appropriate for relaxing - Inappropriate for relaxing } \\
\text { Appropriate for working - Inappropriate for working } \\
\text { Appropriate for chatting - Inappropriate for chatting }\end{array}$ \\
\hline
\end{tabular}




\section{Analysis Of The EXPERIMENTAl ReSUlts}

\subsection{Experimental Results}

Figure 14 shows the average value and standard error of the answers to the nine questions about "how did you feel about the lighting" (white: LED stand lighting, light gray: art lighting 1, deep gray: art lighting 2).
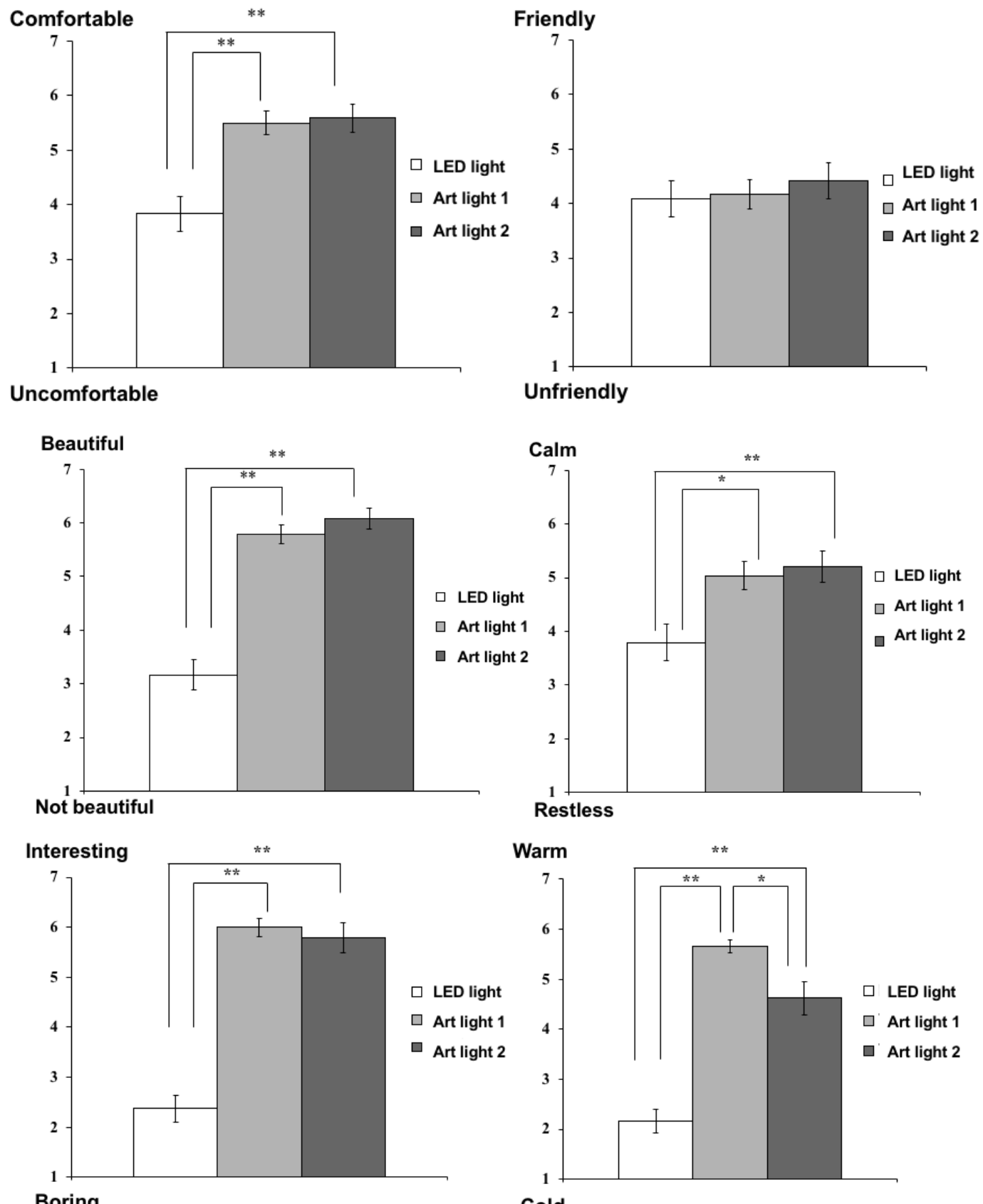

Boring
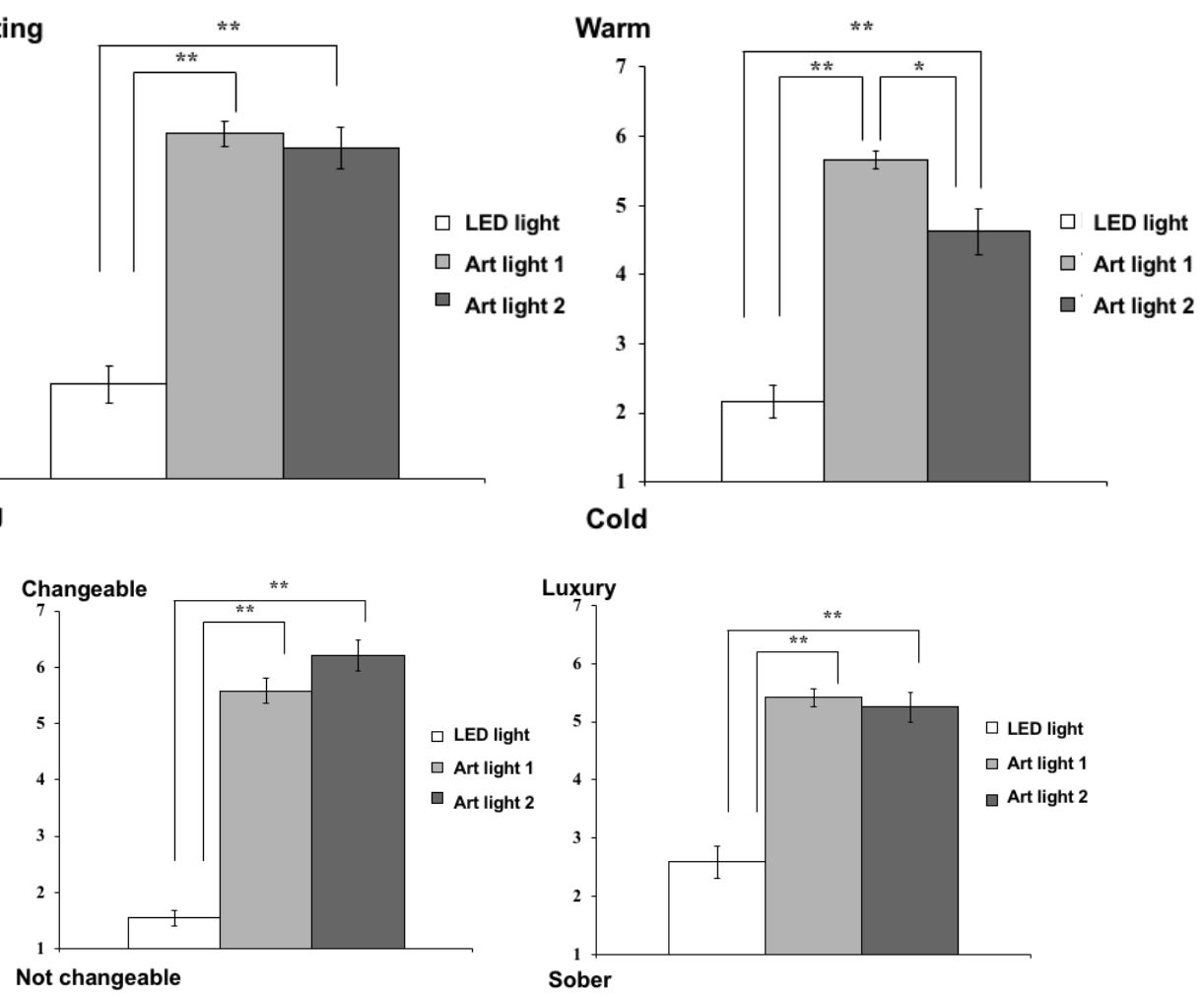


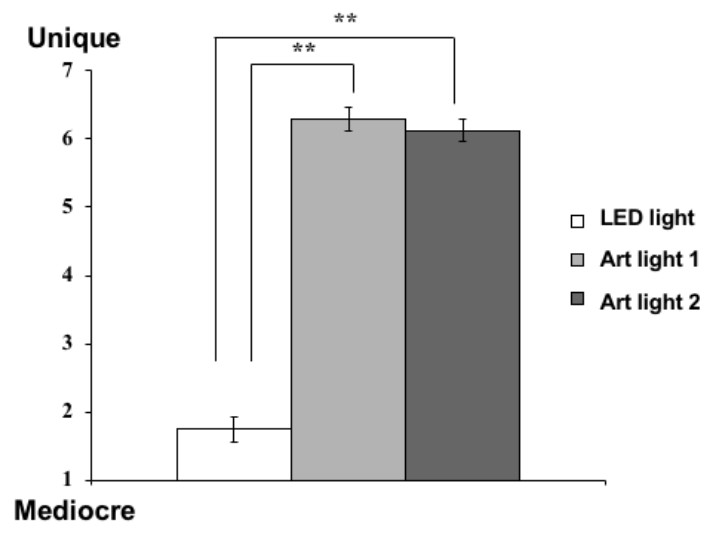

Figure14. Answers to "How did you feelabout the lighting"

Fig. 14 also shows the result of t-test (**: $1 \%$ significance level, *: 5\% significance level).

Figure 15 shows the average and standard error of the answers to the five questions about "What kind of effect does the lighting have?" for each lighting (white: LED stand lighting, light gray: art lighting 1, deep gray: art lighting 2).
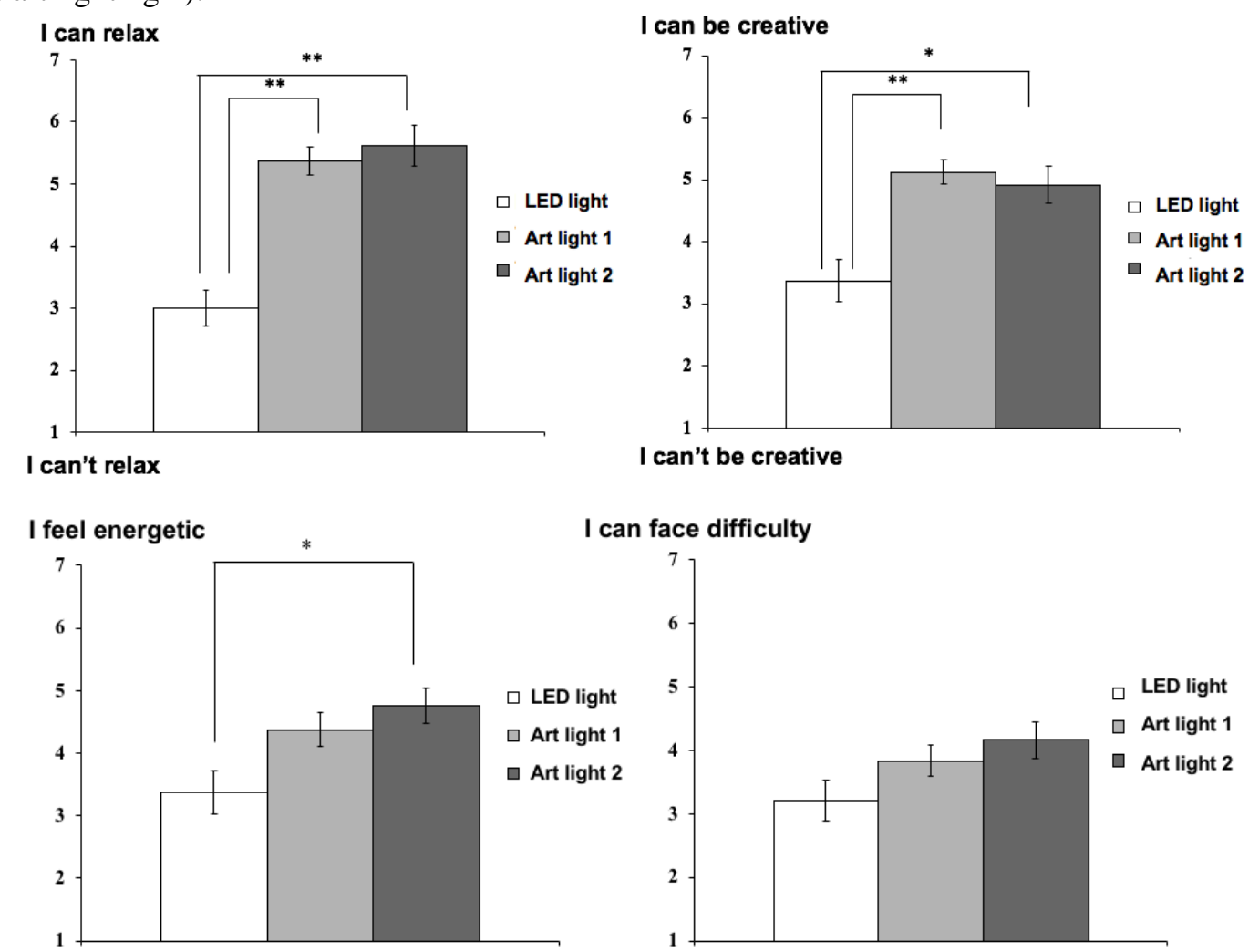

I can face difficulty

I don't feel energetic

I can't face difficulty

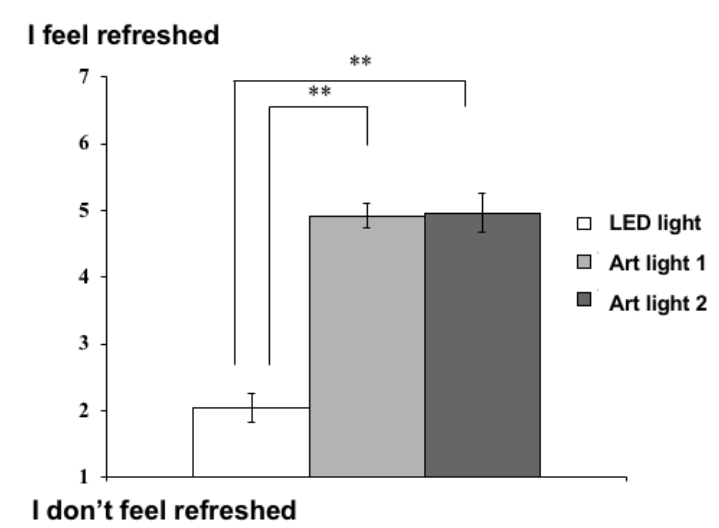

Fig15. Answers to "What kind of effect does the lighting have?" 
Figure 15 also shows the results of t-test (**: $1 \%$ significance level, *: 5\% significance level).

Figure 16 shows the average value and standard error of the answers to the five questions about "What kind of scene is the lighting suitable for?" for each lighting (white: LED stand lighting, light gray: art lighting 1, deep gray: art lighting 2.
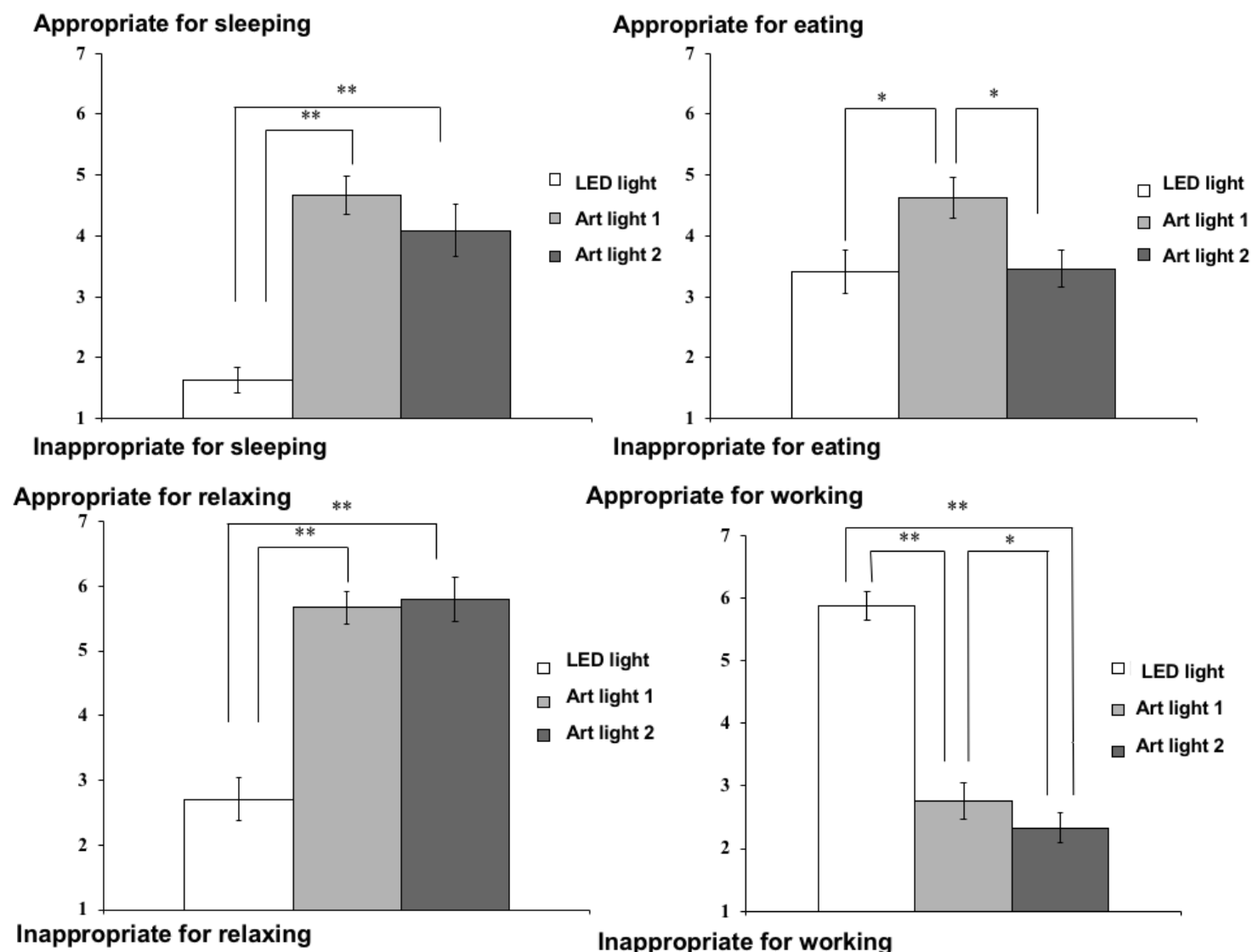

Inappropriate for relaxing

Inappropriate for working

Appropriate for chatting

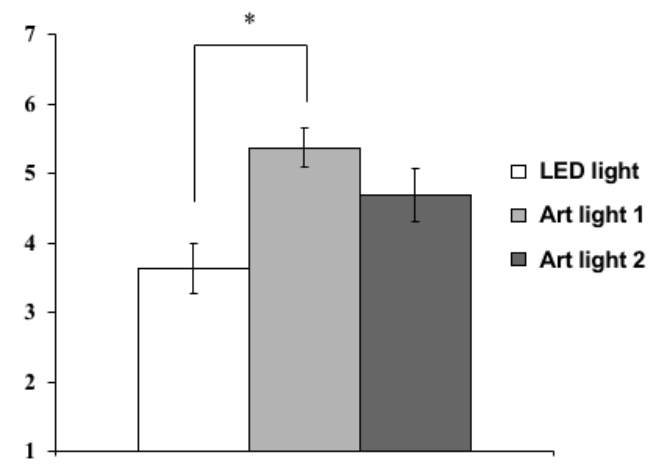

Inappropriate for chatting

Figure16. Answers to "What kind of scene is the lighting suitable for?"

Figure 16 also shows the result of t-test (**: $1 \%$ significance level, *: 5\% significance level).

\subsection{Consideration}

\subsubsection{Consideration on "How did you feel about the lighting?"}

For almost all items, we obtained the result that the art lightings 1 and 2 are favored over the LED lighting at a significance level of $1 \%$. Most of thequestionswere related to whether or not the lighting healssubjects' sensibilities, and it is considered that the questions were more advantageous to the art lightings than the LED lighting. However, regarding "Friendly", there was no significant difference between the art lightings 1, 2, and LED lighting. Probably this is because, since LED lighting is familiar to us in our every day, it is considered that the relatively high evaluation was obtained as compared to the art lightings. 
On the other hand, regarding the difference between the art lightings 1 and 2, there was no significant difference in most items. Since the art lighting 2 incorporates movement into lighting, we expected that there would be a significant difference in terms of questions such as "Changeable." Although there is some difference in the average scores,no significant difference was obtained. How to let people feel the change (including whether it is relevantor not to let them feel this) is considered to be a future study.

\subsubsection{Consideration about "What kind of effect does the lighting have?"}

Regarding the items that have the effect of healing the sensibilities such as "I can relax" and "I feel refreshed", the art lighting 1 and 2 are superior to the LED lighting at a significance level of $1 \%$. It can be said that this is a result similar to the question described in 5.5.1. On the other hand, no significant difference was found for the items related to the willingness of the person, such as "I feel energetic" and "I can face difficulties". However, even so, on the average score, the art lightings 1 and 2 have higher score values than the LED lighting. Moreover, it is interesting to note that the result of the art lightings 1 and 2 are superior to the LED lighting at the significance level of $1 \%$ or 5\% regarding the item "I can becreative." This suggests that art lighting can be used effectively even in work situations, if used properly.

\subsubsection{Consideration on "what kind of scene the lighting is suitable for"}

Regarding the questions of "Appropriate for sleeping" and "Appropriate for relaxing", we obtained the result that the art lightings 1 and 2 are favored over the LED lighting at a significant level of $1 \%$. This is also similar to the results obtained in 5.2.1 and 5.2.2, and therefore is an expected result. On the other hand, concerning the item of "Appropriate for working", the LED lighting is evaluated higher than the art lightings 1 and 2 at a significant level of $1 \%$. This again shows that simple lighting is preferred in the office environment. However, as mentioned in 5.5.2, the art lightings 1 and 2 have better results compared to the LED lighting for the item "I can be creative." This shows the possibility of realizing a work environment that enhances productivity and creativity by introducing art lighting in an office environment. How to realize it would be our future work.

\section{CONCLUSION}

To find out where and for what purpose art lighting, which is a combination of glass art and LED lighting, is suitable for use, we carried out psychological experiments comparing normal LED lighting and two types of art lightings created by us. We constructed two types of environments in our laboratory; one is a working environment for which a normal LED lighting was used and another is relaxing environments for each of which each of art lightings created by us were used. We conducted experiments using 24 subjects by asking them to stay in each of the environments and by asking each of them to answer a questionnaire survey.

Based on the analysis of the questionnaire survey we could obtain several interesting results.

The following are the summary of the results and possible future studies.

(1) This time, we conducted a comparative experiment by separating ordinary LED lighting and art lighting, and we obtained the result that ordinary LED lighting is more suitable in the working environment. However, it was shown that art lighting can make people more creative than simple LED lighting. This means that by combining ordinary LED lighting and art lighting it is possible to improve work efficiency in an environment that is relaxing and stress-free even in an office environment. In the future, it is necessary to consider how art lighting should be introduced into offices by combining ordinary LED lighting and art lighting.

(2) This time, we prepared two types of art lightings, the art lighting 1 and the art lighting 2 , and focused on experiments comparing them with an ordinary LED lighting, so we did not carryout a sufficient comparison between the art lightings 1 and 2. Further studies are needed on what kind of art lighting is suitable for different types of scenes. Also, in that case, it is necessary to classify glass art into several types and examine how they are combined to obtain the expected effect. Evaluation of art is a difficult problem, but we think that it is an unavoidable issue for expanding art to the general society in the future. We would like to study in that direction. 


\section{REFERENCES}

[1] Naoyuki Oi,"The Difference among Generations in Evaluating Interior Lighting Environment," Journal of Physiological Anthropology and Applied Human Science, Vol.24, No.1, pp.87-91 (2005).

[2] Noguchi, H, Sakaguchi, T, "Effect of Illuminance and Color Temperature on Lowering of Physiological Activity,” Applied Human Science, Vol.18, No.4, pp.117-123 (1999).

[3] Morita, T., Tokura, T., "Effects of Light of Different Color Temperature on Nocturnal Changes in Core Temperature and Melatonin in Humans," Applied Human Science, Vol.15, No.5. pp.243-246 (1996).

[4] Kobayashi, H., Sato, M., "Psychological Responses to Illuminance and Color Temperature of Lighting," Journal of Physiological Anthropology, Vol.11, No.1, pp.45-49 (1992).

[5] Freedman, K., "Judgement of Painting Abstraction, Complexity, and Recognition by Three Adult Educational Groups,” Visual Arts Research, Vol.14, pp.68-78 (1988).

[6] Morihiro Okada, Jun Inoue, "A Psychological Analysis about the Elements of Artistic Evaluation on Viewing Paintings," The educational sciences Journal of the Yokohama National University, Vol.31, pp.4566 (1991).

[7] https://en.wikipedia.org/wiki/Glass_production

[8] Gerald W.R. Ward, Dale Chihuly, "Chihuly: Through the Looking Glass," MFA Publications, Museums of Fine Arts, Boston (2011).

[9] Peter S. Bernard, "Fluid Dynamics," Cambridge University Press (2015).

[10] Yunian Pang, Lian Zhao, Ryohei Nakatsu, Naoko Tosa, "A Study on Variable Control of Sound Vibration Form (SVF) for Media Art Creation," 2015 Conference on Culture and Computing, IEEE Press (2015).

[11] Naoko Tosa, Yunian Pang, Qin Yang, Ryohei Nakatsu, "Pursuit and Expression of Japanese Beauty Using Technology," Arts journal, MDPI, Vol.8, No.1, 38(2019).

[12] Mai Cong Hung, Ryohei Nakatsu, Naoko Tosa, Takashi Kusumi, Koji Kyoyamada, "Learning of Art Style Using AI and Its Evaluation Based on Psychological Experiments," Proceedings of IFIP International Conference on Entertainment Computing 2020, pp.308-316 (2020).

[13] Naoko Tosa, Pan Yunian, Ryohei Nakatsu, Akihiro Yamada, Takashi Suzuki, Kazuya Yamamoto, "3D Modeling and 3D Materialization of Fluid Art That Occurs in Very Short Time," Proceedings of IFIP International Conference on Entertainment Computing 2020, pp.409-421 (2020).

Citation: Ryohei Nakatsu, et.al. "Evaluation of Artistic Lighting Combining LED Light and Glass Art by Psychological Experiment" International Journal of Humanities Social Sciences and Education (IJHSSE), vol 8, no. 5, 2021, pp. 76-88. doi: https://doi.org/10.20431/2349-0381.0805009.

Copyright: (C) 2021 Authors. This is an open-access article distributed under the terms of the Creative Commons Attribution License, which permits unrestricted use, distribution, and reproduction in any medium, provided the original author and source are credited. 